\title{
O que são os esquemas de reprodução de Karl Marx?
}

What are the reproduction schemes of Karl Marx?

\section{Giliad de Souza Silva ${ }^{a}$}

\begin{abstract}
Resumo: Este ensaio visa apresentar, de maneira didática, o problema da realização ou de demanda efetiva, que Karl Marx expõe nos últimos capítulos do Livro 2 d'O Capital, através de seus esquemas de reprodução. A hipótese fundamental é que esses esquemas versam sobre auto-reprodução do capital social, cuja limitação é dada por fatores endógenos. As principais conclusões são: (i) que o consumo produtivo importa na análise da realização do capital social e não pode ser negligenciado, como fez Adam Smith; (ii) que os setores responsáveis pela produção das mercadorias consumidas produtivamente (Departamento I) dão a tônica da acumulação de capital que ocorre nos setores responsáveis pela produção das mercadorias consumidas individualmente (Departamento II); (iii) que os esquemas de reprodução apresentam uma parte da teoria marxiana de crise, sendo responsável por apresentar os motivos de tal fenômeno ser endógeno.
\end{abstract}

Palavras-chave: Esquemas de Reprodução; Karl Marx; Demanda Efetiva Classificação JEL: B14, E11, P16

\begin{abstract}
This essay aims to present, in a didactic way, the problem of realization or effective demand, which Karl Marx exposes in the last chapters of Vol. 2 of Capital, through his reproduction schemes. The fundamental hypothesis is that these schemes deal with the self-reproduction of social capital, whose limitation is given by endogenous factors. The main conclusions are: (i) that productive consumption matters in the analysis of the realization of social capital and cannot be neglected, as Adam Smith did; (ii) that the sectors responsible for the production of goods which are productively consumed (Department I) set the tone for the accumulation of capital that occurs in the sectors responsible for the production of goods individually consumed (Department II); (iii) that the reproduction schemes present a part of the Marxian crisis theory, being responsible for presenting the reasons why such phenomenon is endogenous.
\end{abstract}

Keywords: Reproduction Schemes; Karl Marx; Effective Demand JEL Classification: B14, E11, P16

\footnotetext{
a Professor da Faculdade de Ciências Econômicas da Universidade Federal do Sul e Sudeste do Pará
} (FACE/Unifesspa). Email: giliad.souza@unifesspa.edu.br. 


\section{Introdução}

Um dos temas mais polêmicos na teoria marxiana versa sobre o problema da realização ou de demanda efetiva, que Marx expõe nos últimos capítulos do Livro 2 de $O$ Capital (MARX, 1985). Roman Rosdolsky, um relevante pensador social e estudioso dos textos econômicos de Marx, no capítulo 30 de sua obra (ROSDOLSKY, 2001), dedica mais de 50 páginas para apresentar tal controvérsia, sobretudo as questões apresentadas por Rosa Luxemburgo $^{1}$ e Mikhail Tugan-Baranovsky ${ }^{2}$, complementada por Rodolf Hilferding, e as posições no debate interno da Rússia do início do sec. XX. O cerne da polêmica versa sobre as possibilidades endógenas de autorreprodução do capitalismo, isto é, se o sistema necessita ou não de uma "terceira classe", além dos trabalhadores e capitalistas, para fazer o sistema funcionar. A noção apresentada por Luxemburgo é que o sistema tende a sucumbir por subconsumo (ou superprodução de mercadorias), caso não se introduza uma terceira classe, a saber, os "consumidores externos". Ela criticou Marx, acusando-o de irrealista e que seu sistema gerava uma interpretação de que o capitalismo tenderia ao equilíbrio. A posição inaugurada por Tugan-Baranovsky e complementada por Hilferding, é de que o sistema possui as condições internas de autorreprodução e que não carece de qualquer força externa. O maior problema é que esta linha interpretativa provocou a ideia de que, caso o capitalismo possua um agente regulador que permita que os departamentos produzam e consumam proporcionalmente, as crises são eliminadas ${ }^{3}$.

Mas o que, de fato, Marx disse? A posição de Marx está equivocada e se baseia em uma lógica irrealista e equilibrista, como aponta Luxemburgo, ou entende que o sistema, se regulado por um agente eficiente e racional (como o Estado), pode se reproduzir sem desproporção? A hipótese fundamental deste texto é que os esquemas de reprodução de Marx versam sobre autorreprodução do capital social cuja limitação é dada por fatores endógenos. O capitalismo se reproduz sobre um "fio da navalha", cujas condições de equilíbrio são bastante instáveis e gelatinosas. Ou seja, a exposição dos esquemas de reprodução não versa sobre a necessidade da crise para a dinâmica do sistema (que está exposto na "Lei da Queda Tendencial da Taxa de Lucro"), mas sim sobre a possibilidade teórica de tal crise ocorrer. E esta possibilidade é dada pela desproporção entre a aceleração

\footnotetext{
${ }^{1}$ Filósofa e economista alemã do início do sec. XX, principal referência na formulação marxista da teoria do subconsumo. Seu argumento é de que o consumo social deve ser coincidente com a produção social para que não haja crise. Dado que parte da mais-valia se converte em investimento potencial (não vira consumo individual), é necessário a criação de novos mercados externos, para evitar a crise.
}

${ }^{2}$ Economista russo, contemporânea de Luxemburgo, e participando de um dos debates mais acalorados sobre crise e colapso do capitalismo. Sua posição é refratária a tese do subconsumo, a favor de uma interpretação de que a reprodução do capital gera os mercados necessários para absorver a produção excedente.

3 "Mais tarde, tanto Tugan-Baranowsky como Hilferding argumentam que, já que era a anarquia do capitalismo que conduzia às crises, o planejamento eliminaria as crises. Nas palavras de Hilferding, "o capitalismo organizado" era a solução, e a via parlamentar para o controle do Estado era o meio" (SHAIKH, 1983, p. 21) 
da produção de capital e a aceleração da criação de espaços de reprodução deste mesmo capital.

Uma observação necessária: i) este texto não se propõe a aprofundar o debate sobre a validade ou não dos esquemas de reprodução, como é feito por Trigg (2006 e 2017), Trigg e Hartwing (2010), Hartwing (2004) e Passarella (2016). Ele já parte da hipótese que tal abordagem tem uma importante utilidade teórica e está geneticamente vinculada à leitura de dinâmica capitalista de Marx; ii) este texto não se propõe a adentrar no debate sobre teoria de crises de Marx, como é feito por Trigg (2006) e Passarella (2016), porém exclusivamente apresentar, de modo didático, como Marx entende o problema de realização apresentado entre os capítulos 18 e 21 de O Capital, Livro 2 (MARX, 1985), ou, no jargão macroeconômico, o problema da demanda efetiva. Desse modo, a relevância deste texto está em apresentar didaticamente os esquemas de reprodução de Marx, algo que não é comumente feito na literatura especializada. O que tem sido feito de modo sistemático: salientar características específicas localizáveis nos esquemas de reprodução (BURKETT, 2004; HARTWING, 2004) ou aproximar a interpretação teórica e as representações matemáticas com teorias não marxistas (LIANOS, 1979; PASSARELLA, 2016; SARDONI, 2010; TRIGG, 2006 e 2017; TRIGG e HARTWING, 2010).

Assim como está em Marx (1985, cap. 18 a 21), este texto está organizado em 3 seções, além desta introdução e considerações finais. A primeira apresenta o problema, evidenciando o significado de capital social, o modo como sua reprodução ocorre e o debate de Marx com seus contemporâneos, sobretudo Adam Smith. A segunda discorre sobre reprodução simples do capital social total, ou seja, a reprodução supondo que o mais-valor não se converte em fundos monetários para investimento futuro (acumulação). No caso, quais as condições necessárias para a manutenção do capital social total em níveis constantes. A terceira introduz acumulação na reprodução do capital social total, ampliando-o a níveis crescentes. Será evidenciado que a reprodução ampliada depende do consumo produtivo, secundarizando o papel do consumo individual.

\section{Apresentando o Problema da Reprodução do Capital Social Total}

O ponto de partida da análise do problema da realização é identificar o que de fato objetiva-se realizar, no caso, o capital social total. Este nada mais é do que a síntese ponderada dos capitais individuais (frações autonomizadas, com vida individual) ou a "totalidade dos movimentos de suas frações autonomizadas, das rotações dos capitais individuais." (MARX, 1985, p. 261). A "metamorfose do capital individual, sua rotação, é um elo no ciclo do capital social" (MARX, 1985, p.261). Sobre "síntese ponderada" entende-se não apenas a agregação dos capitais individuais, mas a agregação ponderada pela capacidade de encadeamento de cada capital individual (ou capitais individuais de mesmo setor) a jusante e a montante, tempo de rotação, capacidade de geração de fundos monetários e o tipo de mercadoria gerada (se meios de produção ou "bens de capital", ou meios de consumo). Assim sendo, capital social é a totalidade dos movimentos de suas 
frações autonomizadas, ou a síntese ponderada dos capitais individuais, e é constituído de partes do produto social que repõem capital ou reprodução social, que se expressa como consumo produtivo, e partes que entram no fundo de consumo (consumo individual).

Do ponto de vista do capital individual (olhar microeconômico), seu processo de produção, que tanto é responsável pela criação de novos valores de uso (mercadoria com "utilidade" distinta da sua matéria-prima) e de novos valores ou valor adicionado, e que tem o motivo-lucro como propósito balizador, é responsável pela confecção de produtos ou serviços. Desta perspectiva, é irrelevante a natureza desta mercadoria (seu valor de uso), se é um meio de produção ou um meio de consumo. É válido destacar que cada movimento do circuito do capital individual ocorre de modo não coincidente. Neste caso, "o capitalista individual pode primeiramente, por meio da venda de seu produto-mercadoria, converter em dinheiro os componentes de seu capital e então, recomprando no mercado os elementos de produção, retransformá-los em capital produtivo." (MARX, 1985, p. 292). Ou seja, a fase de acesso aos mercados de bens e serviços comprando meios de produção e a de trabalho contratando força de trabalho, como demandante, é não coincidente com a fase de acesso ao mercado de bens e serviços vendendo suas mercadorias, como ofertante. Logo, a hipótese de que ganhos de produtividade em um setor não impacta o valor e preço da força de trabalho (logo, os salários reais) é uma hipótese válida.

O capital social total (olhar macroeconômico), no seu processo de reprodução, deve repor o capital constante, mediante consumo produtivo ("reprodução social" ou reprodução do capital social), e atender as necessidades individuais, quer sejam elas básicas ou luxuosas, mediante consumo individual. Neste caso, faz diferença se o conjunto das mercadorias produzidas objetivam reproduzir o capital (meios de produção) ou reproduzir os indivíduos (meios de consumo). Desse modo, na análise da reprodução do capital social total, é relevante discriminar a natureza da mercadoria produzida (valor de uso), assim como os setores responsáveis por produzi-las. Além disso, do ponto de vista do capital social, cada movimento do circuito do capital individual ocorre de modo coincidente. Como afirma Marx (1985 p. 292-3, acréscimo próprio),

\footnotetext{
[a] retransformação de parte do valor dos produtos em capital, a entrada de outra parte no consumo individual da classe capitalista bem como no da classe trabalhadora constituem um movimento dentro do próprio valor dos produtos em que resultou o capital total; e esse movimento não é apenas reposição de valor, mas também reposição de matéria, sendo assim condicionado tanto pela proporção recíproca dos componentes de valor do produto social como por seu valor de uso, sua forma material.
}

Deste ponto de vista (macroeconômico), o acesso aos mercados de um capitalista individual, ofertando ou demandando, encontra um movimento espelhado por outro capitalista individual, tornando os circuitos coincidentes. Por exemplo, a fase ofertante de bens e serviços por um capitalista individual é também a fase de demandante de bens e serviços de um consumidor (consumidor produtivo - que demanda meios de produção - ou consumidor individual - que demanda produtos finais) e, do ponto de vista do capital social, isto se dá de modo concomitante. Caso não seja assim, há algum tipo de desproporção 
setorial. Como o olhar é macroeconômico, a hipótese de que ganhos de produtividade não necessariamente impactam valor e preço da força de trabalho (FT) é inválida.

\section{Tabela 1: Capital Individual vs. Capital Social Total}

\begin{tabular}{l|c|c}
\hline \hline & Capital individual & Capital social total \\
\hline Olhar econômico & Micro & Macro \\
\hline Natureza da mercadoria & Irrelevante & Relevante \\
\hline Movimento do circuito & Não coincidente & Coincidente \\
\hline Aumento de produtividade & Obter lucro extra & Rebaixar o valor da FT \\
\hline \hline
\end{tabular}

Fonte: Marx (1985). Elaboração própria.

Antes de avançar, alguns destaques são necessários. Primeiro, ao longo do Livro I de $O$ Capital, Marx faz uma série de incursões teóricas que, para tornar o conteúdo mais didático, assume algumas hipóteses facilitadoras. Nos 2 livros subsequentes (Livro 2 e Livro 3 de $O$ Capital), o autor flexibiliza várias dessas hipóteses, dado que a complexificação do conteúdo analisado implica introdução de pressupostos que exigem flexibilizar outros. Ou seja, o que é feito por Marx em $O$ Capital nada mais é do que uma prática recorrente na exposição cientifica de um tema, visando torna-lo mais palatável ao leitor. Porém, diferentemente do que ocorre com a teoria econômica convencional, esse processo não implica a invalidação das formas mais simplificadas. Pelo contrário.

A complexificação incorpora mais camadas explicativas, tornando as formas simplificadas pressuposto para as formas complexas. Segundo é que a diferenciação feita pela Ciência Econômica, convencionalmente, entre fenômenos macro e microeconômicos, atualmente tão cristalina na teoria, não era algo executado pela Economia Clássica, de onde Marx herda seu escopo. A principal ênfase de estudo que a Teoria Clássica e Marxista possuía era a detecção de regularidades econômicas, não importando se tais regularidades estavam compreendidas dentro das rotinas das unidades econômicas individuais ou no agregado delas. Não à esmo que a Teoria Econômica Clássica também é chamada de Economia Política, tendo em vista que Economia Política é o campo de estudo da Economia que visa localizar as regularidades econômicas ("leis econômicas") para explicar fenômenos e prever comportamentos. Por isto, não é exagero afirmar que a Teoria Clássica e Marxista representa a Economia Política por excelência.

Pois bem, abordando especificamente o primeiro destaque, é possível citar algumas hipóteses que foram flexibilizadas ao longo do Livro 2 de $O$ Capital: Hip. 1: distinguir as formas de aparência do capital é irrelevante. No caso, o capital estar na forma dinheiro ou na forma mercadoria não possuía diferenças funcionais significativas; Hip. 2: apontar os efeitos da circulação do capital é irrelevante. Aqui significa dizer que capitalista vende as mercadorias pelo preço de mercado equivalente ao preço social (valor expresso em termos monetários) e sempre encontra os meios de produção para prosseguir a reprodução. Cabe destaque o mercado de trabalho não se enquadra nesta hipótese, pois já fora abordado Livro 1 de $O$ Capital; Hip. 3: o movimento do capital social total emula o movimento do capital individual. 
Na seção 1 do Livro 2, a hipótese 1 é flexibilizada, dado que "foram consideradas as diferentes formas que o capital assume em seu ciclo e as diferentes formas desse mesmo ciclo" (MARX, 1985, p. 262). Na seção 2 do Livro 2, a segunda hipótese é flexibilizada, posto que "ciclo foi examinado como sendo periódico" (MARX, 1985, p. 262). O objetivo da seção 3 do Livro 2, onde se encontra a discussão sobre os esquemas de reprodução, é justamente flexibilizar a hipótese 3, posto que, mesmo nas outras seções do Livro 2, sempre foi tratado o capital individual. Mais especificamente, o objetivo da seção 3 do Livro 2 é "examinar [...] o processo de circulação (que em sua totalidade é forma do processo de reprodução) dos capitais individuais como componentes do capital social total, portanto o processo de circulação desse capital social total." (MARX, 1985, p. 263).

Do ponto de vista do capital-dinheiro, o capital social total é condicionado em diversos aspectos. Cabe destacar 2 deles, a saber, i) o capital é adiantado na forma monetária e; ii) dada a duração da rotação do capital e dos seus componentes (produção e circulação), o adiantamento e renovação do capital na forma monetária difere dado o volume de capital produtivo que ele põe em movimento. Na circulação capitalista, insumos industriais (força de trabalho e meios de produção) precisam ser continuamente comprados e repostos com dinheiro. Mas a escala de produção independe do volume do capital monetário em funcionamento, ou seja, capital real e capital monetário não necessariamente são coincidentes (Marx retoma este tema ao tratar sobre capital de empréstimo e capital a juros). O que importa é a quantidade de valor adicionado. Cabe apontar que o valor social (preço social ou preço de regulação) da mercadoria $i$ qualquer $\left(P S_{i}\right)$ é tal que,

$$
\begin{aligned}
& P S_{i}={c^{\prime}}^{\prime}{ }_{i}+y_{i} \\
& c^{\prime}{ }_{i}=\sum_{i=1}^{n} d_{i}\left(P S_{i} \cdot M P_{i}\right) \\
& y_{i}=\lambda_{i}^{T} \cdot E M T M \\
& \lambda_{i}^{T}=h_{i} \cdot g c_{i} \cdot{ }^{\prime} n_{i}
\end{aligned}
$$

sendo que

$c^{\prime}{ }_{i}$ : valor do capital constante $i$ consumido (2), ou seja, parte dos meios de produção que são cristalizados na nova mercadoria;

$y_{i}$ : valor novo de $i$, criado pelo processo de produção, ou valor adicionado (3). Este valor adiciona, na ótica das remunerações é equivalente a renda $=v_{i}+m_{i}$, para $v_{i}$ : capital variável para o capitalista e salário (forma de renda) para o trabalhador e $m_{i}$ : mais-valor; $d_{i}$ : taxa de depreciação do meio de produção $i$. Caso $d_{i}=1$, o meio de produção é integralmente consumido em uma rotação de capital, ou seja, é capital circulante. Caso $0<$ $d_{i}<1$, o meio de produção é consumido parcialmente em uma rotação de capital, ou seja, é capital fixo;

$\lambda_{i}^{T}$ : valor intrínseco ou quantidade de trabalho social materializado;

EMTM: expressão monetária do trabalho materializado, ou seja, é a expressão, em termos monetários, da quantidade total de trabalho social materializado nas mercadorias;

\footnotetext{
${ }^{4}$ Equações [3] e [4] elaboradas a partir de Maldonado e Marquetti (2017).
} 
$h_{i}$ : tempo modal que o trabalho $T$ leva para produzir a mercadoria $i$, ou tempo de trabalho socialmente necessário ${ }^{5}$;

$g c_{i}$ : grau de complexidade para a execução da atividade de trabalho $T$ para produzir a mercadoria $i$. Caso $g c_{i}=1$, então esta atividade é trabalho simples. Se $g c_{i}>1$, então esta atividade é trabalho complexo;

$i n_{i}$ : intensidade de trabalho, ou seja, o tempo realmente trabalhado por hora em cima da intensidade média, ou "ritmo" de trabalho. Supondo que, em média, para uma atividade de trabalho $T$, os trabalhadores trabalham com ritmo de 40 minutos por hora, $i n_{i}=1$ representa 40 . Um aumento de intensidade de $20 \%$, $i n_{i}=1,2$, muda o ritmo para 48 minutos por hora.

Logo, o valor adicionado do capital social global está em função do tempo de trabalho (extensivo e intensivo) e da produtividade média dos setores. $\mathrm{O}$ aumento de 1 unidade monetária de capital adiantado pode, assim, aumentar o produto final em um número superior a 1. Ademais, o motivo-lucro produz, como comportamento regular das unidades capitalistas, a redução dos custos laborais, isto é, constituem condições de produção sistematicamente mais eficientes. Dado isto, a produção precisa se dar em escala cada vez maior, o que, por sua vez, demanda maior necessidade de centralização de capital (fusões e aquisições). Cresce a massa de capital monetário adiantado pelo capitalista individual, mas sem que o volume total do capital monetário tenha que crescer. Ainda, se se reduz o tempo de rotação, o mesmo capital monetário coloca mais capital produtivo em movimento.

Trocando em miúdos, a taxa de crescimento da massa de capital monetário não necessariamente expressa a taxa de crescimento de capital real, pois deve-se ter em conta que o tamanho do valor adicionado está em função de variáveis distintas do tamanho da massa de capital monetário. Mas isto não implica completa autonomia do capital monetário em relação ao capital real. Revela que as duas esferas possuem autonomia relativa, porém uma impactando a outra. "Perturbações no mercado de dinheiro paralisam, portanto, tais negócios, enquanto esses mesmos negócios, por sua vez, provocam perturbações no mercado de dinheiro" (MARX, 1985, p. 265).

Ainda assim, é necessário destacar que analisar o capital social implica a análise do fluxo monetário ${ }^{6}$, quer seja funcionando como capital, repondo materialmente os meios de produção consumidos na rotação e comprando a força de trabalho, que na produção converte-se em capital constante (que transfere valor) e capital variável (que adiciona

\footnotetext{
${ }^{5}$ Nos livros de $O$ Capital, Marx usou tempo médio enquanto tempo modal, apontando que, nos seus exemplos, a tecnologia com eficiência média é a moda estatística. No entanto, este foi um artifício usado para fins didáticos. Na medida em que capitais funcionam pelo motivo-lucro, no caso a busca persistente pela mais-valia extraordinária (ou lucro extra), que se reflete na prática sistemática de usos de tecnologias que reduzam os custos unitários. Dada a teoria de capital desenvolvida por Marx e deduzindo os casos de setores onde existe poder de monopólio, na prática, o tempo modal é estabelecido pela tecnologia de maior eficiência.

${ }^{6}$ Como afirma Moseley (1998, p. 171), “This question was focus of Marx's previous discussions of Smith's dogma and is clearly concerned with flow of money" ["Esta questão foi o foco das discussões anteriores de Marx sobre o dogma de Smith e está claramente relacionada com o fluxo de dinheiro" tradução própria].
} 
valor), quer seja funcionando como rendimento (salário e mais-valor dedicada a consumo individual), comprando bens de consumo necessário (salário e uma parte do mais-valor) e bens de consumo de luxo (outra parte dos lucros) ${ }^{7}$. Mesmo quando é abordado a respeito da reprodução das mercadorias (meios de produção e meios de consumo), Marx não o faz especificando a quantidade física de insumos e produtos, mas a quantidade monetária de insumos e produtos.

Cabe, adicionalmente, apresentar as posições dos teóricos antecessores a Marx sobre o problema da demanda efetiva ou realização do produto total. É válido destacar dois, Quesnay, com seu Tableau Économique, e Smith. É provável que Quesnay seja o primeiro pensador de relevo a refletir sobre a necessidade de reprodução do produto total anual enquanto um problema de realização (ou de demanda efetiva). A ênfase dada por Quesnay está na necessidade de manutenção da escala da produção do capital social (reprodução simples), ou seja, na necessidade de manter a produção de mais-valor em escala constante e sem acumulação. Para tanto, ele localizou o setor realmente produtivo.

Conforme a apresentação sobre Quesnay feita por Marx (1985, p. 267), "a agricultura é a única esfera de investimento do trabalho humano produtora de mais-valor, portanto, segundo o ponto de vista capitalista, a única realmente produtiva”. Embora cometesse o erro de restringir à agricultura a capacidade de produção de mais-valor, vale salientar que o esquema fisiocrático foi o primeiro a conceber sistematicamente a produção capitalista. E como seria este esquema fisiocrático, sinteticamente? Ele parte da classe dos arrendatários (capitalistas agrários), que dirige o movimento econômico; tem na agricultura, cuja prática capitalista é modus operandi, cujo cultivador direto é o trabalhador assalariado; a produção cria valor novo (não apenas valor de uso); e a produção dá-se pelo motivo-lucro (neste caso, pelo motivo-mais-valor), ou seja, o mais-valor é o objetivo da produção e ela mesma nasce na produção. $\mathrm{O}$ esquema fisiocrático apresenta a necessidade de reprodução do capital social, porém não indica o modo que isto ocorre, cabendo a teóricos posteriores responderem esta questão.

Um destes, que possui destaque na consolidação da teoria econômica enquanto campo científico e que intenta responder este ponto, é Adam Smith. Para fins didáticos, Smith se restringe a análise da reprodução simples (manutenção do capital em funcionamento). Seu ponto de partida é diferenciar renda bruta, que do ponto de vista da identidade contábil é o produto total, de renda líquida, que deduz os gastos com reposição de capital fixo e parte do capital circulante (insumos, matérias-primas, etc.), restando a parte do valor que remunera da força de trabalho e o excedente econômico em termos monetários (mais-valor). Assume, por hipótese, que há um setor produtivo que produz meios de produção sem consumir insumos, no caso, não há capital constante consumido (nem capital constante circulante e nem capital fixo em depreciação). Há apenas o uso de força de trabalho. Dado que este setor seria o fornecedor elementar de insumos, todos os

\footnotetext{
7 "Marx also emphasized that the reproduction of the total social Money capital also involves the reproduction of the material elements of production, especially the means of production." (MOSELEY, 1998, p. 172). ["Marx também enfatizou que a reprodução do capital dinheiro social total também envolve a reprodução dos elementos materiais de produção, sobretudo os meios de produção", tradução própria].
} 
valores dos meios de produção poderiam ser reduzidos à forma de renda (salário, lucro e renda da terra). Qualquer meio de produção poderia ser decomposto, em termos de valor, no somatório das rendas dos setores a montante (que produzem os componentes de seus produtos). O que importa, a partir desta ótica, é o valor adicionado em cada ramo, já que, contabilmente, valor adicionado (lado da produção) é idêntico à renda. Partindo de (1) e (2), e assumindo a hipótese de que há um setor ("hipótese do setor 1") que é o produtor de meios de produção e não consome capital constante no processo de produção de seu produto, $\operatorname{logo}, c_{1}^{\prime}=0$, tem-se

$M^{\prime}{ }_{1}=v_{1}+m_{1}$, ou seja, o valor total de 1 equivalente ao valor adicionado = renda;

$M^{\prime}{ }_{2}=M_{1}^{\prime}{ }_{1}+v_{2}+m_{2}$, onde $M^{\prime}{ }_{1}$ é o capital constante consumido por $M_{2}^{\prime}$, ou seja,

$M_{2}^{\prime}=\left(v_{1}+v_{2}\right)+\left(m_{1}+m_{2}\right)$. Desse modo, o valor da mercadoria $i$ qualquer seria, $M^{\prime}{ }_{i}=\left(v_{i}+v_{i-1}+v_{i-2}+\cdots+v_{i-n}\right)+\left(m_{i}+m_{i-1}+m_{i-2}+\cdots+m_{i-n}\right)$

$$
M^{\prime}{ }_{i}=\sum_{i=1}^{n} v_{i}+\sum_{i=1}^{n} m_{i}
$$

Sendo

$$
y_{i}=\sum_{i=1}^{n} v_{i}+\sum_{i=1}^{n} m_{i}
$$

$\log$,

$$
M^{\prime}{ }_{i}=y_{i}
$$

Esta é a "Solução de Smith" , no caso, reduzir o produto total em valor adicionado, por meio da hipótese do setor 1 (setor fornecedor de insumo básico que produz sem consumir capital constante, $c_{1}^{\prime}=0$ ), assumir a identidade entre produto total (valor adicionado) e renda total, (6), e dissolver o valor tanto do produto individual como social em formas de renda (sobretudo salário, lucro e renda da terra).

Por meio desta solução, i) o dispêndio produtivo perde sua relevância, já que ele foi deduzido da análise, restando apenas do dispêndio individual; ii) a renda se converte em fonte original para todo valor, ao invés de parte constitutiva, (1), e, nos termos de Marx (1985, p. 277), "com isso foram amplamente abertas as portas para a Economia vulgar"; e, iii) a produção, sob este prisma, não mais é entendida como produto do trabalho, mas oriunda da renda. De fato, a Solução de Smith secundariza a relevância do consumo produtivo, posto que este dispêndio não possui identidade com qualquer tipo de renda, não responde como o capital fixo é reposto e faz desaparecer da análise a parte constante do capital. O produto deixa de ser trabalho materializado, cristalizado, sendo exclusivamente o trabalho em ação, que do ponto de vista da produção é valor adicionado e é idêntico contabilmente à renda. Daqui parte a sua noção de Preço Natural.

\footnotetext{
${ }^{8}$ Moseley (1998) denomina esta saída como o "Dogma de Smith".
} 
Como toda a soma de trabalho anual se dissolve em trabalho necessário à reprodução do valor-capital despendido em força de trabalho e em trabalho necessário à criação de maisvalia, de onde proviria ainda ao todo o trabalho para a produção de um valor-capital não despendido em força de trabalho? (MARX, 1985, p. 278).

É notório que esta Solução dada por Smith é insuficiente para responder o problema da realização do produto ou a questão da demanda efetiva. A "hipótese do setor 1" é logicamente questionável e empiricamente inverificável. Mesmo os setores com atividades extremamente intensivas em trabalho (atividades agrícolas e extrativistas com baixa incorporação de tecnologia, e.g.) faz uso de algum tipo de insumo ou ferramenta (meio de produção), ou seja, consome produtivamente.

A retirada analítica do capital constante gera apenas imprecisão no entendimento do fenômeno (problema da realização ou da demanda efetiva) e pouca robustez na localização de fatores explicativos. Mesmo o entendimento de que é possível reduzir todo produto à renda, parte da identidade contábil entre renda e valor adicionado (3) e (5.1) e este, por sua vez, nada mais é do que o trabalho em ação, (3). Ademais, é necessário diferenciar capital de renda. Se o salário, para o trabalhador, representa uma renda, a mercadoria que ele "aluga" ao capitalista e é adquirida por parte do capital adiantado (adiantado ao processo de produção), representa capital (na produção, é capital variável).

Ao capitalista, salário é capital monetário. Para o trabalhador, é renda. Nada naturalmente é capital. Força de trabalho funciona tanto como mercadoria na venda (quando o capitalista contrata o trabalhador) como capital, criador de valor nas mãos do capitalista, no caso, quando está em atividade, operando os meios de produção. Em síntese, Marx descarta a solução dada por Smith e encaminha sua resposta a partir de outros marcos.

\section{Reprodução Simples}

Após apresentar o problema, Marx (1985, cap. 20) constrói seu argumento respondendo, inicialmente, como é possível que a realização do produto seja tal que mantenha, no mínimo, nos mesmos patamares, no caso, que a reprodução ocorra sem acumulação de capital (conversão de parte do mais-valor em capital adicional). Como é possível, em outras palavras, a reprodução simples? Para tanto, seu ponto de partida é entender como se dá a reposição do capital (mediante consumo produtivo, no caso, investir) e como esta se entrelaça com o consumo individual (dos capitalistas e trabalhadores), em termos de produto. Para tanto, ele trabalha com as seguintes hipóteses: (i) o mais-valor produzida é convertida integralmente em consumo dos capitalistas (ou seja, é reprodução simples); (ii) os produtos se realizam com preços de venda equivalentes aos valores ou 
preços sociais, como descrito em $\left(1^{9}\right.$; (iii) tecnologia constante ${ }^{10}$, no caso, assume-se que a reprodução não altera as proporções entre os componentes do valor. Por mais que estas hipóteses simplificadoras tenham um caráter didático, o caso da hipótese (i), é relevante para entender o movimento real "à medida que ocorre acumulação, a reprodução simples constitui sempre parte da mesma, podendo, portanto, ser examinada em si mesma e é um fator real da acumulação." (MARX, 1985, p. 293).

Do ponto de vista algébrico, a hipótese (i) pode ser expressa da seguinte forma:

$$
\begin{gathered}
y_{i}=y_{i} k+y_{i} t \\
y_{i}=m_{i}+v_{i} \\
y_{i} k=\alpha y_{i} k+\omega y_{i} k \\
m_{i}=u_{i}+\omega \cdot m_{i}
\end{gathered}
$$

onde,

$y_{i} k$ ou $m_{i}$ é a renda dos capitalistas (mais-valor), parte-alíquota da renda total;

$y_{i} t$ ou $v_{i}$ é a renda dos trabalhadores (capital variável), parte-alíquota da renda total;

$\alpha$ é a propensão a consumir dos capitalistas e $0 \leq \alpha \leq 1$;

$\alpha y_{i} k=u_{i}$ é o montante de mais-valor dedicado ao consumo dos capitalistas;

$\omega=1-\alpha$ é a propensão a acumular dos capitalistas, ou seja, propensão a dedicar parte do mais-valor para formação de fundos, objetivando convertê-lo em capital novo (consumo produtivo). Deste modo, se $\alpha=1$ e $\omega=0, \operatorname{logo}$, esse sistema está em reprodução simples.

A produção do capital social pode ser decomposta em departamentos, no caso, em ajuntamento de setores econômicos responsáveis pela produção de produtos de mesma natureza (ver tabela 1). Assim, o Departamento I (D1) é o produtor de meios de produção ou de "mercadorias que possuem uma forma em que têm de entrar ou pelo menos podem entrar no consumo produtivo" (MARX, 1985, p. 293). É o responsável por produzir mercadorias que ingressarão no processo produtivo como capital constante e visa atender a necessidade de dispêndios produtivos (= investimento) por parte do capital. Sendo uma indústria produtora de energia ou uma firma produtora de máquinas, ambas são constitutivas do D1. O Departamento II (D2), por sua vez, é o produtor de meios de consumo que atinge diretamente o consumidor final ou de "mercadorias que possuem uma forma em que entram no consumo individual da classe capitalista e da classe trabalhadora" (MARX, 1985, p. 293). É o responsável por produzir mercadorias que serão despendidas

\footnotetext{
${ }^{9}$ No caso, sem efeitos da concorrência. Esta é entendida como o processo econômico que estimula os novos capitais a transferir-se de um setor para outro ou de uma firma para outra, motivado por ganhos de rentabilidade. A concorrência gera pressão nos preços relativos, tendo em vista a tendência de que novos investimentos se desloquem i) às indústrias cujas taxas globais de lucro sejam as maiores e; ii) dentro de uma indústria, aos métodos de produção mais eficientes, que reduzem os custos unitários e são replicáveis. O primeiro efeito tende a equalizar as taxas de lucro entre indústrias e o segundo a equalizar os preços de venda intrassetorialmente.

10 “sem revolução no valor dos componentes do capital produtivo" (MARX, 1985, p. 292).
} 
com o agregado da renda. Sendo uma indústria produtora de vestimentas ou uma firma produtora de guarda-chuvas, ambas são constitutivas do D2.

Como é notório, o capital produtivo se constitui de 2 componentes, capital variável $(v)$ que, em termos de valor, "é igual ao valor da força de trabalho social empregada nesse ramo da produção, portanto igual à soma dos salários pagos por aquela” (MARX, 1985, p. 293). Já, em termos de matéria, “consiste na própria força de trabalho em atividade, isto é, no trabalho vivo posto em movimento por esse valor-capital" (MARX, 1985, p. 293). O outro componente é o capital constante $(c)$, que, em termos de valor, é o agregado do "valor de todos os meios de produção empregados para a produção nesse ramo" (MARX, 1985, p. 293). Em termos materiais, “decompõem em capital fixo: máquinas, instrumentos de trabalho, construções, gado de trabalho etc., e em capital constante circulante: materiais de produção, como matérias-primas e auxiliares, produtos semimanufaturados etc." (MARX, 1985, p. 293, ênfases no original). Se compõe assim de parte do capital consumido na produção que transfere valor (por isto constante) e outra que, na produção, cria valor novo ou valor adicionado. Do ponto de vista da oferta, D1 produz mercadorias que são consumidas produtivamente pelos capitais tanto de D1 quanto de D2. O D2, por sua vez, oferta mercadorias que são consumidas individualmente pelos trabalhadores e capitalistas tanto de D1 quanto de D2.

Assumindo que não há capital fixo, ou seja, que todo capital constante é consumido por rotação - depreciação abstraída, $d_{i}=1$, ver $(2)$ - e que as formas monetárias estão habilitadas a funcionarem apenas como meio de troca (não desempenham a função de meio de entesouramento e meio de pagamento) tem-se que o valor global dos meios de produção (MP) e dos meios de consumo (MC) podem ser descritos por:

$$
\begin{array}{ll}
M P=c_{1}+y_{1} & M^{\prime}=M P+M C \\
M C=c_{2}+y_{2} &
\end{array}
$$

onde $c$ representa o valor transferido dos meios de produção ao produto total e $y$ o valor adicionado (三 renda) pela produção.

No entanto, é possível observar a dinâmica nos 2 departamentos pela ótica das despesas e fornecimentos, ou seja, por matriz de insumo-produto. Supondo uma matriz A de ordem 2 com a seguinte composição:

Tabela 2: Matriz A de insumo-produto da economia com 2 departamentos

\begin{tabular}{c||c||c||c}
\hline \hline $\mathbf{A}$ & $\mathbf{I}$ & $\mathbf{I I}$ & Total (oferta) \\
\hline $\mathbf{I}$ & $c_{1}$ & $c_{2}$ & $D 1^{o}$ \\
\hline $\mathbf{I I}$ & $y_{1}$ & $y_{2}$ & $D 2^{o}$ \\
\hline Total (demanda) & $D 1^{d}$ & $D 2^{d}$ & $M^{\prime}$ \\
\hline \hline
\end{tabular}

Fonte: Marx (1985). Elaboração própria. 
As linhas da Tabela 2 representam o total fornecido por aquele departamento, enquanto que as colunas representam o total das despesas. Por exemplo, $c_{2}$ (coluna 2, linha 1), do ponto de vista do fornecimento (ou oferta), representa, em termos de valor, o total de meios de produção ofertado por D1 que virarão capital constante no processo de produção do D2. Do ponto de vista do dispêndio, significa o montante total gasto por D2 para adquirir meios de produção ao seu processo de produção, que se tornará capital constante. É oferta de meios de produção por D1 (olhar a linha) e é demanda por D2 (olhar a coluna). O mesmo vale para $y_{1}$. É oferta de meios de consumo por D2 (olhar a linha) e é demanda por D1 (olhar a coluna).

Lado da oferta:

$$
\begin{aligned}
& D 1^{o}=c_{1}+c_{2} \\
& D 2^{o}=y_{1}+y_{2}
\end{aligned}
$$

Lado da demanda:

$$
\begin{aligned}
& D 1^{d}=c_{1}+y_{1} \\
& D 2^{d}=c_{2}+y_{2}
\end{aligned}
$$

Para que um departamento funcione de modo equilibrado com toda a economia, tudo que ele fornece (seu valor bruto da produção - VBP) deve ser igual ao total de sua demanda (agregado de pagamentos e despesas). Igualando oferta (produto total setorial) de demanda (despesa total setorial) do D1 e do D2, ou seja, (11.1 e 11.2) e (12.1 e 12.2), temse que,

$$
y_{1}=c_{2}
$$

O que [13] expressa é a Condição de Equilíbrio Interdepartamental ou $\mathbf{1}^{\mathbf{a}}$ Condição de Equilíbrio para que o produto total seja realizado e a demanda global se efetive. Isto significa dizer que, em termos de valor, D1 deve despender recursos em meios de consumo de D2 $\left(y_{1}\right)$ de modo equivalente aos meios de produção que oferta ao D2 $\left(c_{2}\right)$. Os valores dos meios de produção consumidos produtivamente por D2 devem se corporificar em uma quantidade de valores equivalentes aos meios de consumo demandados por D1 para que a quantidade de mercadorias produzidas seja realizada do ponto de vista global.

O raciocínio por trás é relativamente simples: para que uma economia esteja equilibrada, do ponto de vista da demanda efetiva e da realização do produto total, tudo que um departamento produz e não consume internamente ( $c_{1}$ para D1 e $y_{2}$ para D2) deve ser consumido pelo outro departamento para que não haja problema de realização. $\mathrm{O}$ valor adicionado em termos de produto do D1 (meios de produção) deve ser insumo consumido por D2 (capital constante) de modo idêntico, em termos de valor, ao dispêndio em meios de consumo (produzidos por D2) pelos trabalhadores (salários) e capitalistas (lucros) do D1. Este dispêndio do outro departamento em meios de produção e meios de consumo $\left(c_{2}\right.$ 
e $y_{1}$ ) deve constituir a demanda planejada de cada departamento para que haja equilíbrio entre a demanda planejada e a demanda efetiva.

Alguns destaques são necessários. Primeiramente, não se pode partir de um pressuposto de equilíbrio para entender como o problema da realização é resolvido. $\mathrm{Ou}$ seja, a condição de equilíbrio não pode ser entendida como uma pré-condição do problema. Essa rotina se dá por turbulências e oscilações, tendo a condição de equilíbrio como um centro de gravidade. Se a demanda efetiva garantir a realização de todo o valor produzido, então verificar-se-á a condição de equilíbrio. Ou seja, esta igualdade se dá de modo não antecipável. Segundo, pela análise da reprodução simples (reprodução do capital social na ótica da manutenção de seu funcionamento) fica evidente que a realização do capital social não está singularizada na realização dos meios de consumo. Não apenas a dedução do consumo produtivo da análise, feita pela "Solução de Smith", implica um erro lógico, como, do ponto de vista do raciocínio econômico, prejudica o entendimento do processo que conduz a reprodução do capital social. Este, por sua vez, não apenas repõe as mercadorias necessárias para reprodução dos indivíduos (meios de consumo), mas deve também repor as condições necessárias para reprodução do capital, por meio da produção de meios de produção. Este destaque aponta a divergência entre Marx e a Solução de Smith, como também antecipa a resposta a abordagem subconsumista marxista (crítica da crítica).

Como visto na Introdução, esta abordagem entende que o capitalismo estaria fadado a impossibilidade de autorreprodução, já que sempre seria necessário a criação de novos mercados para escoar a superprodução de mercadorias. Esta interpretação i) negligencia o consumo produtivo, assim como é feito pela Solução de Smith e; ii) entende que a reprodução do capital social implica a sistemática produção de meios de consumo, esquecendo da produção das condições necessárias para reprodução do capital. A construção teórica feita por Marx parte do pressuposto que o capitalismo é um sistema que tem condições de se autorreproduzir, no entanto, em cima de condições instáveis e turbulentas. O que a $1^{\mathrm{a}}$ Condição de Equilíbrio expõe é que a limitação à autorreprodução sistêmica ocorre por fatores endógenos. Na medida em que esta condição de equilíbrio não é satisfeita, capitais individuais ficam impossibilitados de "proverem uns aos outros as condições para a continuidade dos seus circuitos" (CIPOLLA; AQUINO, 2007, p. 7). Ou seja, o capitalismo é capaz de se autoexpandir, porém, de modo autolimitado. "Os limites do capitalismo são internos a ele (SHAIKH, 1983, p. 6).

Como já foi dito, (13) expressa a condição de equilíbrio interdepartamental para que o capital social mantenha sua reprodução em níveis constantes (taxa de crescimento nula, $g_{k}=0$ ). As outras duas variáveis da Matriz A (tabela 2) não explicadas por (13) devem ser citadas. Uma delas, $y_{2}$, deve ter seu valor despendido em meios de consumo individual. Estes estão na forma-mercadoria e equivalem, em termos de valor, a $y_{2}$, que na mão dos capitalistas de D2 repõe o capital que foi adiantado na forma-salário e formam seus fundos de consumo. Do ponto de vista da reprodução do capital social, este processo desaparece no próprio D2 um montante de valor, em termos de mercadoria, equivale a $y_{2}$. Logo, $y_{2}$ é o valor equivalente de produto-consumo no próprio D2. 
Por sua vez, os meios de produção demandados por D1, dado em termos de valor, equivale a $c_{1}$ e visa repor seu capital constante consumido. "[P]or isso, são liquidados mediante o intercâmbio mútuo entre os capitalistas individuais de I" (MARX, 1985, p. 295, acréscimo próprio), assim como ocorre com $y_{2}$. Porém há um detalhe relevante que conduz o tratamento destas duas variáveis $\left(c_{1}\right.$ e $\left.y_{2}\right)$ em modos distintos. Enquanto que os meios de produção não se diferenciam do ponto de vista de natureza entre si, os meios de consumo $\operatorname{sim}$.

Os bens de consumo podem ser meios de subsistência necessário ou artigos de luxo. Isto remonta para a necessidade de existir uma segunda condição de equilíbrio que atue no D2, de modo que o valor adicionado por D2 $\left(y_{2}\right)$, em termos de mercadoria, seja plenamente realizado pela renda criada pelo próprio departamento. Trocando em miúdos, os dispêndios executados para consumo individual pelos salários dos trabalhadores e lucros dos capitalistas de D2 devem se dar de modo tal que o total dos artigos de luxo e meios de subsistência ofertados pelos capitalistas deste departamento sejam consumidos em sua plenitude.

Sabendo que $y_{2}=v_{2}+m_{2}$ e que D2 pode ser decomposto em dois subdepartamentos, a saber, $D 2_{A}$, responsável pela produção de meios de subsistência necessários, adquiridos pelos salários dos trabalhadores e parte dos lucros de capitalistas (já que um capitalista não vive apenas de lanchas e afins), e $D 2_{B}$, responsável por produzir artigos de luxo, consumidos pela outra parte dos lucros de capitalistas. Cada subdepartamento constitui-se de unidades econômicas responsáveis pela produção das respectivas mercadorias. Logo, em $D 2_{A}$ existem unidades econômicas, com trabalhadores e capitalistas de $D 2_{A}$, assim como em $D 2_{B}$, existem unidades econômicas, com trabalhadores e capitalistas de $D 2_{B}$, de modo que:

Tabela 3 - Matriz B dos 2 subdepartamentos de D2

\begin{tabular}{c|c|c|c}
\hline \hline $\mathbf{B}$ & $\boldsymbol{I}_{\boldsymbol{A}}$ & $\boldsymbol{I I}_{\boldsymbol{B}}$ & Total (oferta) \\
\hline $\boldsymbol{I I}_{\boldsymbol{A}}$ & $v_{2 A}$ & $v_{2 B}$ & $D 2_{A}^{o}$ \\
\hline $\boldsymbol{I I}_{\boldsymbol{B}}$ & $m_{2 A}$ & $m_{2 B}$ & $D 2_{B}^{o}$ \\
\hline Total (demanda) & $D 2_{A}^{d}$ & $D 2_{B}^{d}$ & $y_{2}$ \\
\hline \hline
\end{tabular}

Fonte: Marx (1985). Elaboração própria.

Para que a produção de meios de consumo destinada a atender os dispêndios internos ao D2, a oferta e demanda dos subdepartamentos de meios de subsistência $\left(D 2_{A}\right)$ e artigos de luxo $\left(D 2_{B}\right)$ devem ser tais que:

Equilíbrio entre oferta e demanda:

$$
\begin{aligned}
& D 2_{A}^{d}=D 2_{A}^{o}=v_{2 A}+v_{2 B}+\eta_{2 A}^{\prime} \cdot m_{2 A}+\eta_{2 B}^{\prime} \cdot m_{2 B} \\
& D 2_{B}^{d}=D 2_{B}^{o}=\left(1-\eta_{2 A}^{\prime}\right) \cdot m_{2 A}+\left(1-\eta_{2 B}^{\prime}\right) \cdot m_{2 B}
\end{aligned}
$$


onde,

$\eta^{\prime}$ é propensão à subsistência dos capitalistas, ou seja, razão dos gastos de consumo individual dos capitalistas com meios de consumo necessário;

$\left(1-\eta^{\prime}\right)$ é propensão ao luxo dos capitalistas, ou seja, razão dos gastos de consumo individual dos capitalistas com meios de consumo de luxo;

$v_{2 A}$ e $m_{2 A}$ são os componentes do valor adicionado pelas indústrias produtoras de meio de subsistência; e,

$v_{2 B}$ e $m_{2 B}$ são os componentes do valor adicionado pelas indústrias produtoras de artigos de luxo.

Assumindo que os capitalistas de ambos os subdepartamentos têm a mesma propensão à subsistência $\left(\eta^{\prime}{ }_{2 A}=\eta^{\prime}{ }_{2 B}=\eta^{\prime}\right)$, as equações de equilíbrio entre oferta e demanda dos subdepartamentos do departamento D2 ficam:

Equilíbrio entre oferta e demanda:

$$
\begin{aligned}
& D 2_{A}^{d}=D 2_{A}^{o}=v_{2}+\eta^{\prime} \cdot m_{2} \\
& D 2_{B}^{d}=D 2_{B}^{o}=\left(1-\eta^{\prime}\right) \cdot m_{2}
\end{aligned}
$$

Desse modo, (15.1) e (15.2) expressam o Equilíbrio Intradepartamental ou $\mathbf{2}^{\mathbf{a}}$ Condição de Equilíbrio para que o produto total seja realizado e a demanda global se efetive. Esta condição de equilíbrio é a garantia de que toda produção de meios de consumo individual seja devidamente demandada, considerando as diferenças na natureza destas mercadorias. Cabe destacar que o equilíbrio intradepartamental deve ser válido também para os dispêndios em meios de consumo executados por D1. Deste modo, a demanda de D1 por artigos de consumo, quer seja de subsistência, quer seja de luxo, cujo valor se expressa em $y_{1}$, deve também se dar de modo equilibrado à oferta, cujo valor se expressa em $c_{2}$. Ademais, o fato de que uma parte de $m_{2}$ ter de se converter em meios de subsistência cria impacto intradepartamental, mas também interdepartamental. A $2^{\mathrm{a}}$ Condição de Equilíbrio condiciona a participação dos subdepartamentos em D2, logo condiciona também a transição entre meios de consumo de D2 com os meios de produção de D1. De algum modo, o Equilíbrio Intradepartamental condiciona (e é condicionado) pelo Equilíbrio Interdepartamental. Ou seja, a $2^{a}$ Condição de Equilíbrio, "afeta, pois, o caráter e as relações quantitativas da produção até as raízes e é um momento que determina essencialmente sua estrutura global" (MARX, 1985, p. 304).

Alguns resultados teóricos da reprodução simples podem ser resumidos da seguinte forma: i) se oEquilíbrio Interdepartamental ou $1^{\text {a }}$ Condição de Equilíbrio não for respeitada, ao ponto que o "novo produto-valor do trabalho anual" de D1 não seja "reproduzido em forma de meios de consumo" (MARX, 1985, p. 302), pode haver superprodução em D2, $c_{2}>y_{1}$, de modo que D2 não poderia repor seu capital constante. Ou pode haver subconsumo em D2, $c_{2}<y_{1}$, de modo que D1 produziria um valor adicionado não utilizado integralmente; ii) a parte do valor adicionado pelo subdepartamento produtor de artigos de luxo proporcional ao capital adiantando com força de trabalho que, na produção, aparece como capital variável, $v_{2 B}$, só se converte em capital 
monetário caso o Equilíbrio Intradepartamental ou $2^{\text {a }}$ Condição de Equilíbrio seja respeitada. Ou seja, parte do valor adicionado de $D 2_{B}$ só é realizado se houver produção e realização (demanda efetiva) de modo que não gere superprodução ou subconsumo em $D 2_{B}$. Dada a hipótese da reprodução simples, se faz necessária outras 2 hipóteses: i) "que a escala e as proporções de valor da produção permaneçam estacionária"; ii) "que essas condições rígidas não sejam alteradas pelo comércio exterior.” (MARX, 1985, p. 302). Ou seja, tecnologia constante e que as condições de oferta e demanda não sejam alteradas pelo comércio exterior.

Algumas ressalvas a serem ditas. Dada a $2^{\text {a }}$ Condição de Equilíbrio (Intradepartamental), não é pressuposto que a propensão à subsistência $\left(\eta^{\prime}\right)$ dos capitalistas seja invariável ao longo dos subdepartamentos. Neste caso, como afirma Marx (1985, p. 302-3),

e modo algum é pressuposto que sejam os capitalistas individuais de $D 2_{A}$ e $D 2_{B}$, sejam suas respectivas coletividades, eles dividam na mesma proporção sua mais-valia entre artigos de consumo necessários e artigos de luxo. Um pode gastar mais no consumo destes, outro mais no consumo daqueles.

A hipótese de igualdade na propensão à subsistência entre os capitalistas de D2 é sobretudo para fins didáticos. Outra ressalva diz respeito a participação de $D 2_{B}$ no produto total anual pari passu as oscilações na propensão ao luxo $\left(1-\eta^{\prime}\right)$ dos capitalistas produtores de meios de subsistência.

\begin{abstract}
Da circunstância de que IIbv $\left[v_{2 B}\right]$, se realiza em uma parte equivalente de IIam $\left[m_{2 A}\right]$, segue que, na proporção em que aumenta aparte de luxo do produto anual, em que, portanto, um quotum crescente de força de trabalho é absorvido na produção de luxo - que na mesma proporção a reconversão do capital variável adiantado em IIbv $\left[v_{2 B}\right]$, em capital monetário, que funciona de novo como forma-dinheiro do capital variável, e, com isso, a existência e a reprodução da parte da classe trabalhadora ocupada em IIb $\left[D 2_{B}\right]$ - sua oferta de meios de consumo necessários é condicionada pela prodigalidade da classe capitalista, pela transação departe considerável de sua mais-valia por artigos de luxo. (MARX, 1985, p. 303).
\end{abstract}

Cabe destacar que, este desenvolvimento teórico da reprodução simples evidencia que D1 não apenas cumpre o papel de fornecedor de insumo para D2 (como é possível interpretar, baseado na Solução de Smith ou nas leituras subconsumistas do marxismo). Ou seja, a expansão na produção de meios de produção não implica aumento proporcional da capacidade de produção dos meios de consumo. Meios de produção também são usados para produzir meios de produção, como é evidenciado pela Tabela 2, pelo componente $c_{1}$.

Outra questão baseada nesta análise é que subconsumo não se deve a uma incapacidade "natural" que o capitalismo tem para realizar todo produto na renda, no caso, realizar algo que é persistentemente maior do que a renda. Mesmo que toda renda líquida fosse possuída pela classe trabalhadora (que não possui capacidade de acumular), ainda assim uma parte do produto não seria consumido pela renda. Isto porque parte do produto é consumido pelo próprio capital, enquanto consumo produtivo. O que subconsumo 
representa é uma desproporção interdepartamental ou intradepartamental. Ainda assim, não é possível afirmar, baseado em uma interpretação marxiana, que crises econômicas são possíveis por existir excesso de salário (interpretação feita pela abordagem profit squeeze) ou sua escassez (interpretação subconsumista), como é visto na nota de rodapé 5. Fato é que o capitalismo é contraditório e independe da "boa ou má vontade que permitem aquela relativa prosperidade da classe trabalhadora só momentaneamente e apenas como pássaro agoureiro de uma crise." "11 (MARX, 1985, p. 304).

Outro elemento relevante, e diz respeito à resposta a Solução de Smith, é que a reprodução simples evidencia que o produto total não é demandado apenas para satisfazer o consumo individual, mas também para atender as necessidades do consumo produtivo. Ou seja, produto total não pode ser igualado à renda total pois apenas a necessidade de consumo não produtivo seria atendida. Em síntese, a realização do produto total deve tanto atender a necessidade de manutenção dos indivíduos (circuito da renda) quanto a necessidade de reposição dos meios de produção (circuito do capital). Tal realização só se dá caso haja equilíbrio interdepartamental (13) e intradepartamental (15.1 e 15.2). Esta "Solução de Marx" se evidencia pelo fato de que D1 tanto consome as mercadorias de D2 (como é previsto por Smith), quanto consome também seus próprios produtos, os meios de produção. Ou seja, ambos os departamentos têm a possibilidade realizar o consumo individual assim como o consumo produtivo, mediante reposição do capital constante. Se a forma aparente preço social (1), com o devido ajuste da concorrência intersetorial ${ }^{12}$, se constitui de preço de custo (capital constante consumido + capital variável) e lucro apropriado, logo, a receita do capital individual deve ser tamanha que reponha os custos (reposição dos meios de produção [capital fixo depreciado + capital constante circulante] e da força de trabalho, mediante pagamento de salários) e se aproprie do lucro.

\footnotetext{
11 "se se procura dar a essa tautologia a aparência de fundamentação mais profunda, dizendo que a classe trabalhadora recebe parte demasiadamente pequena de seu próprio produto e o mal seria remediado tão logo ela obtivesse maior participação nele, aumentando, em consequência, seus salários, basta observar que as crises são sempre preparadas justamente por um período em que os salários sobem de modo geral e a classe trabalhadora obtém realiter participação maior na parte do produto anual destinada ao consumo. Tal período deveria - do ponto de vista desses cavaleiros do sadio e 'simples' (!) senso comum - ao contrário, afastara crise. Parece, portanto, que a produção capitalista contém condições independentes de boa ou má vontade que permitem aquela relativa prosperidade da classe trabalhadora só momentaneamente e apenas como pássaro agoureiro de uma crise.” (MARX, 1985, p. 304).

${ }^{12}$ Cabe salientar que, a esta altura, do ponto de vista analítico, Marx não introduz a concorrência entre capitais, tema que só será tratado no Livro 3 d'O Capital.
} 


\section{Acumulação e Reprodução Ampliada}

$\mathrm{Na}$ sessão anterior, foram apresentadas as condições para que a reprodução do capital social (produto total) ocorresse de modo a manter o capital em níveis constantes, ou seja, sem acumulação de mais-valor. A garantia de tal processo dar-se-ia por 2 condições de equilíbrio (ex post), apresentadas em (13) e (15.1 e 15.2). Sabe-se que, por mais que seja necessário a manutenção do capital enquanto uma garantia para que o sistema funcione minimamente, a acumulação é condição vital. Assim como ocorre com o capital do ponto de vista individual, no caso, a retransformação do mais-valor em elementos "naturais adicionais de seu capital produtivo" (MARX, 1985, p. 357) - transformação do mais-valor em investimento potencial (= acumulação), isto também deve aparecer na reprodução do capital global, ou seja, na reprodução do capital social. Neste caso, parte do mais-valor deve ser consumida produtivamente. Desse modo, a propensão a acumular dos capitalistas, expresso em (8), deve ser tanto que $0 \leq \alpha<1$, flexibilizando, assim, a hipótese (i) da reprodução simples. Logo, a reprodução ampliada supõe a reprodução simples (manutenção dos níveis mínimos de reprodução) e inclui transformação de parte do maisvalor na expansão das condições de produção instalada. A renda dos capitalistas $\left(y_{i} k\right)$ serve tanto para consumo individual quanto para consumo produtivo.

São duas as precondições para que haja acumulação, ou seja, para que o mais-valor se converta em novo capital, a saber, (i) que o montante seja suficiente para expandir a planta industrial existente (= expandir a condição de produção existente) ou para abrir uma nova planta (estabelecer nova condição de produção), dada a tecnologia existente (condições técnicas). Caso o montante seja insuficiente, gera-se fundos para tal empreitada (fundos de acumulação e fundos de depreciação). De toda sorte, deve haver capital, na forma líquida, em montante suficiente para ampliar a capacidade instalada; (ii) que haja disponibilidade no mercado para a acumulação, no caso, haja meios de produção (quer seja pronto, quer seja para encomenda) para manter e expandir a escala. Ou seja, é necessário a formação de novo capital monetário potencial, por meio dos fundos, ao capitalista individual. "[P]otencial em virtude de sua capacidade e determinação de converter-se em elementos do capital produtivo." (MARX, 1985, p. 358, acréscimo próprio). Desse modo, fica patente que, no processo de acumulação, a formação de fundos (tesouro capitalista) é uma característica persistente do sistema capitalista.

O ponto de partida para entender o processo de acumulação é analisando tal processo no interior de D1, departamento produtor de meios de produção, no caso, das mercadorias que visam atender a necessidade do consumo produtivo (= investimento) do capital. Deve-se partir do entendimento de que os capitais investidos nos setores industriais do D1 são heterogêneos, dadas as rotações já decorridas. Mesmo abstraindo o volume dos investimentos, a tecnologia envolvida (condições técnicas de produção), condições de mercado, etc., o tempo de produção e/ou circulação podem ser díspares. Esta heterogeneidade implica produção diversa de fundos e de maturação destes fundos ao ponto de gerar reinvestimento. Tem-se 2 capitalistas, A (com fundos em maturação) e B (com fundos maturados). Capitalistas A imobilizam, por necessidade técnica, uma parcela dos 
fundos monetários, criando uma parcela de capital real ocioso (condição de produção instalada), privando este capital, "por mais ou menos tempo, de sua capacidade de circular" (MARX, 1985, p. 359). A produção de excedente, em termos de mercadoria (maisproduto), é pressuposto para este processo capitalista de entesouramento (produção de fundos monetários). No caso, converte este mais-produto (excedente em termos de mercadoria), por meio da venda, em mais-valor (excedente em termos monetários), mas não o re-transforma de imediato em produto. Por isto tal mais-valor converte-se em fundos monetários, dado que é capital potencial à espera de ser acionado para converter-se em condição de produção ${ }^{13}$.

$\mathrm{O}$ fato de haver um processo persistente de geração de fundos supõe que, na circulação, nem toda venda implica uma compra subsequente, ou seja, a demanda efetiva pode diferir da demanda planejada. Logo, oferta e demanda agregada podem se cruzar fora da plena utilização da capacidade instalada (pleno emprego). Uma divergência entre demanda planejada e demanda efetiva revela também que o dinheiro cumpre funções relevantes fora da circulação, enquanto fundos monetários ou capital potencial (= entesouramento no modo de produção capitalista), e que mercadoria não se troca por mercadorias. Ou seja, trocas mercantis implicam divergência espacial e temporal dos atos de compra e venda, logo,

a conversão dos diversos componentes do produto anual, isto é, sua circulação [...] não supõe, de modo algum, mera compra de mercadoria completada por venda subsequente, ou mera venda completada por compra subsequente, de modo que, de fato, só haveria troca de mercadoria por mercadoria, como presume a Economia Política, nomeadamente a escola livre-cambista, desde os fisiocratas e Adam Smith. (MARX, 1985, p. 360).

Isto fica evidente ao recorrer a Tabela 2 (Matriz A) e observar o elemento $a_{1,1}$ (produzido por D1 e despendido por D1), $c_{1}$, no caso, o elemento que revela a produção de D1 que é consumida pelo próprio departamento. Os capitalistas com fundos em maturação (A) de D1 vende seu mais-produto (excedente na forma de mercadoria) e entesoura, dado que não possui a quantidade necessária de capital dinheiro para convertê-lo em capital real adicional. Apenas os capitalistas com fundos maturados (B) de D1 podem comprar este mais-produto de A, o que transforma seu capital potencial (fundos monetários) em elementos de capital produtivo adicional. Esta hipótese sobre a existência de dois tipos de capitalistas possuidores de fundos com momentos diferentes de maturação (A - com fundos

\footnotetext{
${ }^{13}$ Entesouramento não é um processo uniforme ao longo dos modos de produção. Apenas no capitalismo que ele assume uma forma potencial de riqueza e não riqueza em si. Dado que riqueza no capitalismo é capital, valor que se autovaloriza e deve ficar em persistente movimento, o fato de um montante monetário ficar ocioso significa que ele não está participando da autoexpansão do valor, logo, ele não expressa uma forma de riqueza em si, mas riqueza potencial. Como afirma Silva (2017, p. 52), "[n]ão é o desejo de acumular dinheiro ocioso que motiva a formação de reservas pelos capitalistas individuais, no entanto é uma condição ou resultado do processo de reprodução dos capitais, imposto pelo sistema. Ademais, nesta função ele não se constitui como dinheiro estéril, enquanto mera reserva, porém é capital monetário, isto é, 'capital potencial na sua forma monetária'. Essas reservas, que se desdobram de uma necessidade imposta aos capitalistas, do ponto de vista individual, fazem o dinheiro funcionar como meio de entesouramento na economia capitalista."
} 
em quantidade inferior ao necessário para expandir ou renovar as condições de produção; B - com fundos em quantidade adequada para expandir ou modernizar as condições de produção) torna possível a aquisição de capital adicional de modo a viabilizar a acumulação de capital em D1. Esta operação deve ser tal que o excedente de A, na forma produto, seja idêntico ao excedente de B, na forma dinheiro, de modo que,

$$
m_{1 A}=m_{1 B}
$$

onde,

$m_{1 A}$ : excedente de A, na forma de mais-produto (meio de produção adicional);

$m_{1 B}$ : excedente de $\mathrm{B}$, na forma de mais-valor (dispêndio produtivo adicional).

O que (16) expressa é a Condição para o Autofinanciamento da Acumulação em D1 e evidencia sob qual hipótese é possível que haja consumo produtivo adicional. Neste caso, supondo que a tecnologia é dada, para que haja acumulação em D1 é necessário que haja equilíbrio entre o fluxo de fundos para acumulação e a produção de bens de capital e matérias-primas (meios de produção) que expandem a capacidade instalada (dispêndio produtivo adicional, $m_{1 B}=$ meio de produção adicional, $\left.m_{1 A}\right)$. Considerando que $D 1_{A}$ (capitalistas com fundos em maturação) produz todo montante dos meios de produção adicional de D1, este mais-produto (excedente na forma de mercadoria) só se converte efetivamente em capital constante adicional quando é consumido produtivamente por $D 1_{B}$ $\left(D 1_{A}\right.$ é fornecedor de $\left.D 1_{B}\right)$.

Dada esta hipótese, é presumível que os meios de produção consumidos por D2 $\left(c_{2}\right)$, que é equivalente ao valor adicionado por $\mathrm{D} 1,(13)$, é produzido por $D 1_{B}$. Porém, ao invés de D1 converter todo valor adicionado em meios de consumo, parte do mais-valor converte-se em fundos monetários para acumulação. Esta é a fonte de maturação dos fundos de $D 1_{B}$. Cabe destacar que a distinção feita entre capitalistas (um com fundos em maturação e outro com fundos maturados) não diz respeito a uma diferença qualitativa (capitalistas financiadores VS capitalistas executores ${ }^{14}$ ), mas uma diferença de posição. No tempo passado $\left(t_{-1}\right)$, aquele capitalista que estava maturando seus fundos e que no tempo presente ( $t_{0}$ ou apenas $\left.t\right)$ está com fundos maturados, no tempo futuro $\left(t_{l}\right)$ estará maturando mais uma vez seus fundos e aqueles que estavam maturando no tempo presente $\left(t_{0}\right)$ estará com fundos maturados no tempo futuro $\left(t_{l}\right)$ e assim sucessivamente.

É de se supor que dentre estes elementos de capital produtivo adicional que é incorporado por $D 1_{B}$, ou seja, que a acumulação existente entre os capitalistas com fundos maturados, deve tanto ampliar qualitativa ou quantitativamente os meios de produção quanto contratar mais pessoas. Ou seja, para ocorrer a acumulação, é necessário estender ou intensificar não apenas os meios de produção, isto é, ampliar/modernizar a planta

\footnotetext{
${ }^{14}$ Esta distinção qualitativa ao incluir o conceito "juro" e de capital monetário portador de juros, algo excluído por hipótese. Esta distinção qualitativa entre capitalistas proprietários do capital e capitalistas que fazem o capital funcionar Marx faz na seção V do Livro III de $O$ Capital "Divisão do Lucro em Juro e Lucro do Empresário O Capital Portador de Juros".
} 
industrial ou criação de nova planta, mas a força de trabalho, através de contratação de mais pessoas com mesma qualificação ou outras mais qualificadas, para colocar esses meios de produção adicionais em movimento. Logo, para que este capital produtivo adicional apareça como capital constante, é necessário adicionar também capital variável. Apenas pelo fato de existir exército industrial de reserva (EIR) ou força de trabalho suplementar não plenamente absorvido pelo mercado de trabalho ativo, que é possível transformar capital monetário na forma de fundos em capital variável. Muito embora não seja tema deste texto apresentar o conceito de EIR, é suficiente "admitir que a parte do capital monetário recém-formada, que é transformável em capital variável, sempre encontra disponível a força de trabalho em que deve se transformar" (MARX, 1985, p. 365).

Outro elemento relevante é que a condição de autofinanciamento, que é válida para D1 também deve existir em D2 para que não exista desproporção setorial. No entanto, esta condição de autofinanciamento para D2 tem uma particularidade: ela ocorre seguindo a dinâmica de D1. Ou seja, a condição de autofinanciamento de D1 é líder e a de D2 é seguidora.

Conforme Marx (1985) e Harris (1972), é possível derivar as seguintes equações:

1) Investimento em capital produtivo:

$$
\begin{aligned}
& I_{i}^{t}=c_{i}^{t}+v_{i}^{t} \\
& c_{i}^{t}=c_{i}^{t-1}+\Delta c_{i} \\
& v_{i}^{t}=v_{i}^{t-1}+\Delta v_{i} \\
& \Delta I_{i}=\omega \cdot m_{i}^{t-1}=\Delta c_{i}+\Delta v_{i}
\end{aligned}
$$

onde $I_{i}^{t}$ é gasto corrente com capital produtivo, $c_{i}^{t}$ é o gasto corrente em capital constante pelo departamento i qualquer, $c_{i}^{t-1}$ é o gasto em capital constante no período anterior pelo departamento i e $\Delta c_{i}$ é o capital constante adicional gasto pelo departamento i. As mesmas definições são válidas para os gastos produtivos com capital variável.

2) Determinações do excedente de A e B:

$$
\begin{aligned}
& m_{i A}^{t}=\Delta c_{i} \\
& m_{1 B}^{t}=c_{2}^{t-1}-u_{1}^{t-1}-v_{1}^{t-1}
\end{aligned}
$$

onde $m_{1 A}^{t}$ é o mais-produto de D1 (capital constante adicional) consumido por D1 e $m_{1 B}^{t}$ é o mais-valor de D1 não convertida em meio de consumo, conforme a condição de equilíbrio interdepartamental, [13], e as suposições da condição de autofinanciamento da acumulação de D1. O entendimento é que fundos maturados de D1 $\left(m_{1 B}^{t}\right)$ é um resíduo do seu produto realizado no período anterior em D2 $\left(c_{2}^{t-1}\right)$ em relação a seus dispêndios individuais realizados no período anterior em $\mathrm{D} 2\left(u_{1}^{t-1}+v_{1}^{t-1}\right)$. 
3) Condição de Equilíbrio Interdepartamental:

$$
\begin{aligned}
& y_{1}^{t}=u_{1}^{t}+v_{1}^{t-1}+\omega \cdot m_{1}^{t-1} \\
& c^{t}=c_{1}^{t}+c_{2}^{t}
\end{aligned}
$$

Sendo $u_{1}^{t}=\alpha \cdot m_{i}^{t-1}$. Assumindo que $D 1^{d}=c_{1}^{t-1}+y_{1}^{t}$, que $D 1^{o}=c_{1}^{t}+c_{2}^{t}$ e que departamentos devem igualar seu valor bruto da produção (oferta) com o total dos dispêndios; neste caso, que $D 1^{d}=D 1^{o}$. Usando 17.4, tem-se,

$$
\begin{aligned}
& c_{1}^{t-1}+y_{1}^{t}=c_{1}^{t-1}+\Delta c_{1}+c_{2}^{t-1}+\Delta c_{2} \\
& y_{1}^{t}=c_{2}^{t-1}+\Delta c_{2}+\Delta c_{1} \\
& y_{1}^{\prime t}=v_{1}^{t-1}+\Delta v_{1}+u_{1}^{t-1}+\Delta u_{1}
\end{aligned}
$$

Incorporando [16], [18.1] e [19.5] em [19.4], tem-se,

$$
\begin{aligned}
& y_{1}^{\prime t}+m_{1 B}^{t}=c_{2}^{t-1}+\Delta c_{2}+\Delta c_{1} \\
& v_{1}^{t-1}+u_{1}^{t-1}+\Delta v_{1}+\Delta u_{1}+m_{1 B}^{t}=c_{2}^{t-1}+\Delta c_{2}+\Delta c_{1}
\end{aligned}
$$

onde $\Delta c_{2}$ é o capital constante adicional de D2 realizado com os fundos maturados pelos capitalistas B de D2, $u_{1}^{t-1}$ é o fundo de consumo dos capitalistas de D1 no período passado e $\Delta u_{1}$ é o fundo de consumo adicional dos capitalistas de D1. O valor adicionado por D1 é equivalente aos meios de consumo que o mesmo demanda para D2 $\left(y_{1}^{\prime t}\right)$ somando o valor equivalente ao dispêndio produtivo (capital constante) adicional de D1, em forma monetária $\left(m_{1 B}^{t}\right)$.

A condição de equilíbrio interdepartamental se expressa pela igualdade entre a magnitude do valor despendido por D1 em meios de consumo de D2 agregando o dispêndio planejado em capital constante adicional $\left(m_{1 B}^{t}\right)$ e o total de meios de produção ofertado por D1 para D2 juntamente a seu capital constante adicional efetivo $\left(\Delta c_{1}\right)$. Ou seja, conforme (19.7), para que haja acumulação com equilíbrio interdepartamental, é necessário que a taxa crescimento dos dispêndios planejados em D1, no caso, do dispêndio planejado em consumo produtivo de capital variável por $\mathrm{D} 1\left(v_{1}^{t-1}+\Delta v_{1}\right)$, dos fundos de consumo dos capitalistas de D1 $\left(u_{1}^{t-1}+\Delta u_{1}\right)$ e do dispêndio planejado em consumo produtivo de capital constante adicional de D1 $\left(m_{1 B}^{t}\right)$, sejam iguais à taxa de crescimento do valor bruto da produção de $\mathrm{D} 1$, no caso, da produção global de meios de produção.

Assumindo (16), (18.1) e (19.6) e deduzindo o excedente de $D 1_{A}=m_{1 A}^{t}=\Delta c_{1} \mathrm{e}$ $D 1_{B}=m_{1 B}^{t}$ tem-se que,

$$
m_{2 B}^{t}=y_{1}^{\prime t}-c_{2}^{t-1}-m_{1 B}^{t}
$$

de modo que [20] revela que a acumulação em D2 é seguidora da acumulação em D1. No caso, os fundos maturados em D2 $\left(m_{2 B}^{t}\right)$ está em função dos fundos maturados em D1 $\left(m_{1 B}^{t}\right)$. Esta é a primeira conclusão relevante da condição de equilíbrio interdepartamental com acumulação. 
Supondo que parte da renda do capital é direcionado à acumulação, (8), e que os gastos departamentais com capital produtivo são direcionados parte para capital constante e outra para capital variável (17.1) a (17.4) tem-se,

$$
\begin{aligned}
& \Delta c_{i}=\theta_{c, i} \cdot \Delta I_{i} \\
& \Delta v_{i}=\left(1-\theta_{c, i}\right) \cdot \Delta I_{i}
\end{aligned}
$$

onde $\theta_{c, i}$ é a proporção do capital constante no capital produtivo adicional do departamento i e $1-\theta_{c, i}$ é a proporção do capital variável do departamento i; $\Delta I_{i}$ é o dispêndio em capital produtivo adicional.

4) Taxa de crescimento do capital produtivo:

$$
\begin{aligned}
& g_{i}^{c}=\frac{\Delta c_{i}}{c_{i}^{t-1}}=\frac{\theta_{c, i} \cdot \omega_{i} \cdot m_{i}^{t-1}}{c_{i}^{t-1}} \\
& g_{i}^{v}=\frac{\Delta v_{i}}{v_{i}^{t-1}}=\frac{\left(1-\theta_{c, i}\right) \cdot \omega_{\cdot} \cdot m_{i}^{t-1}}{v_{i}^{t-1}}
\end{aligned}
$$

multiplicando (23.1) por $\frac{v_{i}^{t-1}}{v_{i}^{t-1}}$ e assumindo que taxa de exploração ou mais-valor $e_{i}^{t-1}=$ $\frac{m_{i}^{t-1}}{v_{i}^{t-1}}$, que a tal taxa é constante no tempo e nos departamentos, $e_{i}^{t-1}=e_{i}^{t}=\hat{e}$, que mudanças na composição-valor do capital ocorrem em função de mudança na composição técnica (composição orgânica do capital) de modo que $k_{i}^{t-1}=\frac{c_{i}^{t-1}}{v_{i}^{t-1}}=f\left(\frac{M P_{i}^{t-1}}{T_{i}^{t-1}}\right)$, que a composição técnica (tecnologia) é constante no tempo, $k_{i}^{t-1}=k_{i}^{t}=k_{i}$, tem-se

$$
\begin{aligned}
& g_{i}^{c}=\frac{\theta_{c, i}}{k_{i}} \omega_{i} \cdot \hat{\mathrm{e}} \\
& g_{i}^{v}=\left(1-\theta_{c, i}\right) \cdot \omega_{i} \cdot \hat{\mathrm{e}}
\end{aligned}
$$

Ou seja, a taxa de crescimento do capital constante em um dado departamento é diretamente proporcional à taxa de exploração, à propensão a acumulação e à proporção do capital constante no capital produtivo adicional, e inversamente proporcional à composição orgânica do capital (composição-valor em função da composição técnica). A taxa de crescimento do capital variável, por sua vez, é diretamente proporcional à taxa de exploração, à propensão a acumulação e à proporção do capital variável no capital produtivo adicional. Caso $k_{i}$ cresça (tecnologia crescente) e tudo mais constante (ou que cresça proporcionalmente menos), a taxa de crescimento do capital constante (logo, do capital produtivo $=$ investimento) tende a cair.

As razões econômicas que explicam esta tendência a queda da taxa de investimento residem no próprio mecanismo básico de funcionamento do capital (motivo-lucro), que Marx apresenta na sua Lei da Queda Tendencial da Taxa de Lucro, tema este que foge ao 
escopo do texto. Cabe destacar que a taxa de investimento é uma função da taxa de lucro $\left(r_{i}\right)$, de modo que (obs.: (24) e (23.5) foram multiplicadas por $\frac{v_{i}}{v_{i}}$ ),

$$
r_{i}=\frac{m_{i}}{c_{i}+v_{i}}=\frac{e_{i}}{1+k_{i}}
$$

E a taxa de investimento é dada por,

$$
g_{i}^{I}=\frac{\Delta I_{i}}{c_{i}^{t-1}+v_{i}^{t-1}}=\frac{\omega_{i} \cdot m_{i}^{t-1}}{c_{i}^{t-1}+v_{i}^{t-1}}=\omega_{i} \cdot \frac{\hat{\mathrm{e}}}{1+k_{i}}
$$

Assumindo [24], tem-se,

$$
g_{i}^{I}=\omega_{i} \cdot r_{i}
$$

No "primeiro exemplo" (MARX, 1985, p. 370-3), o autor assume as seguintes hipóteses: $\hat{\mathrm{e}}=1 ; \omega_{1}=0,5 ; \theta_{c, 1}=0,8 ; \overline{k_{1}} ; c_{1}^{1}=4000$; e $v_{1}^{1}=1000$. Desse modo, temse que:

Tabela 4: exemplos numéricos da reprodução ampliada em D1

\begin{tabular}{c|c|c|c|c|c|c}
\hline \hline Período & $\mathbf{C}$ & $\mathbf{V}$ & $\mathbf{m}$ & $\Delta \boldsymbol{I}\left(\boldsymbol{\omega}_{\boldsymbol{i}} \cdot \boldsymbol{m}_{\boldsymbol{i}}^{\boldsymbol{t}-\mathbf{1}}\right)$ & $\mathbf{r}$ & $\boldsymbol{g}_{\boldsymbol{i}}^{\boldsymbol{I}}$ \\
\hline 1 & 4000 & 1000 & 1000 & - & $20 \%$ & - \\
\hline 2 & 4400 & 1100 & 1100 & 500 & $20 \%$ & - \\
\hline 3 & 4840 & 1210 & 1210 & 550 & $20 \%$ & $10 \%$ \\
\hline 4 & 5324 & 1331 & 1331 & 605 & $20 \%$ & $10 \%$ \\
\hline 5 & 5856,4 & 1464,1 & 1464,1 & 665,5 & $20 \%$ & $10 \%$ \\
\hline \hline
\end{tabular}

Fonte: Marx (1985); Lianos (1979). Elaboração própria.

As conclusões mais relevantes da reprodução ampliada podem ser assim sumarizadas: i) a condição de equilíbrio interdepartamental (19.5) e (19.6) torna viável o funcionamento da acumulação. Esta só pode ocorrer de modo sadio caso a expansão real da produção em D1 garanta a viabilização da demanda efetiva. Ou seja, não apenas a demanda planejada, expressa pelos fundos maturados (18.2), mas pela consumação destes fundos. "[O] mínimo dessa expansão é aquilo sem o qual não seria realizável a acumulação real, isto é, a expansão real da produção em [D1]" (MARX, 1985, p. 376); ii) caso haja diferenças persistentes nas taxas de investimento entre os departamentos, expresso pela execução relativa de fundos, escalas perdem a proporcionalidade e crises tornam-se possíveis. Cabe relembrar que, afirmar a possibilidade da crise não evidencia sua necessidade; iii) a acumulação de D2 é dada em resposta a acumulação de D1.

Assim, como fica evidente em (20), a acumulação que ocorre em D2 é dependente da acumulação que ocorre em D1. É uma interpretação relativamente simples: se acumulação de capital de D2 depende do consumo produtivo e se o consumo produtivo de D2 depende da produção das mercadorias consumidas produtivamente, logo a acumulação 
de D2 depende confecção do mais-produto que são consumidos produtivamente. Como D1 é o departamento responsável para confeccionar tal produção, forma sentido que a acumulação em D2 dependa da acumulação em D1.

\section{Considerações Finais}

Este ensaio buscou apresentar didaticamente a exposição feita por Marx (1985) sobre a reprodução do capital social por seus esquemas de reprodução. A primeira consideração diz respeito à Solução de Smith, que versa sobre a noção de que o capital social pode ser entendido como o agregado dos valores adicionados por todos os capitais individuais. É suposto a hipótese smithiana do setor 1, setor produtor de insumo básico e que não consome meio de produção. Esta Solução ao problema da realização e da demanda efetiva conclui que o produto total seria igual à renda total. As principais consequências analíticas são: i) imprecisão direta do fenômeno, tendo em vista que não há setor produtivo que não consuma meios de produção; ii) secundarização do capital constante na determinação do produto total; iii) não diferenciação entre capital e renda, que implica a não diferenciação do fluxo monetário no circuito do capital e no circuito da renda.

A segunda consideração diz respeito à reprodução simples marxiana ou a "Solução de Marx". Para Marx, produto total não é igual a renda total em virtude de que há a necessidade de reposição do capital constante e tal reposição não está em função da renda. Ou seja, o produto total é realizado tanto pelo circuito da renda quanto pelo circuito do capital. Para que tal realização ocorra, é necessário um equilíbrio interdepartamental e outro intradepartamental, como expresso em (13), (15.1) e (15.2).

A terceira consideração versa sobre a reprodução ampliada. As principais conclusões desta consideração são: i) D1 é o departamento mais relevante em um cenário em que a reprodução do capital social total ocorre com conversão de parte do mais-valor em fundos de acumulação; ii) desproporção interdepartamental (diferenças persistentes nas taxas de investimento entre os departamentos) explicam a endogenia da crise, mesmo que não explique sua necessidade, e; iii) acumulação de D2 ocorre em função da acumulação de D1, inversamente ao que se conclui pela Solução de Smith.

Cabe salientar um elemento importante, enquanto consideração final: não está aqui advogando que a teoria de crise de Marx expressa-se pela Teoria da Desproporção de Baranovski-Hilferding, mas apontando que os esquemas de reprodução explicam uma parte relevante dela: que a crise é um fenômeno endógeno. A interpretação da construção lógica feita por Marx é a seguinte: a crise é possível, a crise é endógena e a crise é necessária. No nível mais alto da abstração, as trocas monetárias implicam a separação entre compra e venda enquanto momentos não coincidentes. Esta divergência torna possível que o valor da mercadoria não seja realizado e a crise apareça como possibilidade. A análise feita aqui (reprodução do capital social e a demanda efetiva), evidencia que a crise é endógena. Ao analisar a tendência a queda da taxa de lucro, a crise aparece como necessidade para 
reprodução do capital social, dado que a taxa de crescimento deste capital se dá em níveis maiores em relação a taxa de criação de possibilidades de sua realização. Isto se expressa na redução tendencial da rentabilidade e pode aparecer de diversas formas. Neste caso, não teríamos diversas teorias de crise, mas apenas uma, porém apresentada em momentos diferentes, dado nível de abstração. A teoria de crise de Marx afirma que ela é possível, endógena e necessária.

\section{Referências}

BURKETT, Paul. Marx's reproduction schemes and the environment. Ecological Economics, vol. 49, p. 457 - 467, 2004.

CIPOLLA, Francisco; AQUINO, Dayani. O desenvolvimento da teoria da possibilidade da crise. In: COLÓQUIO MARX E ENGELS, 5., Campinas. Anais... Campinas: CEMARX, 2007. p. 1-8. Disponível em: http://www.unicamp.br/cemarx/anais v coloquio arquivos/arquivos/comunicacoes/gt1/s essao1/Francisco Cipolla.pdf.

HARRIS, Donald. On Marx's Scheme of Reproduction and Accumulation. Journal of Political Economy, vol. 80, n. 3, p. 505-522, 1972.

HARTWING, Jochen. Keynes's multiplier in a two-sectoral framework. Review of Political Economy, vol. 16, p. 309 - 34, 2004.

LIANOS; Theodore. Domar's Growth Model and Marx's Reproduction Scheme. Journal of Macroeconomics, vol. 1, n. 4, p. 405 - 412, 1979.

MALDONADO-FILHO, Eduardo; MARQUETTI, Adalmir. Introdução à Economia Política: Livro Texto Versão 2.0. Versão Preliminar (mimeo), 2017.

MARX, Karl. O Capital: crítica da Economia Política. São Paulo: Nova Cultural, 1985. (Livro 2, Vol. III).

MOSELEY, Fred. Marx's Reproduction Schemes and Smith's Dogma. In: ARTHUR, Christopher; REUTEN, Geert. (orgs). The Circulation of Capital: Essays on Volume Two of Marx's Capital. Londres/Nova Iorque: Macmillan Press/St. Martin's Press, 1998. p. 159 -185 .

PASSARELLA, Marco V. A Marx 'Crises' Model: The Reproduction Schemes Revisited. Working Paper PKSG, vol. 1610, mai. 2016. Disponível em: 
http://www.postkeynesian.net/downloads/working-papers/PKWP1610 MbJY9lo.pdf. Acesso em: 15 de abril de 2018.

ROSDOLSKY, Roman. Gênese e estrutura de O Capital de Karl Marx. Rio de Janeiro: Contraponto, 2001.

SARDONI, Claudio. The Marxian schemes of reproduction and the theory of effective demand. Cambridge Journal of Economics, vol. 33, p. 161 - 173, 2010.

SHAIKH, Anwar. Uma introdução à história das teorias de crise. Ensaios FEE, vol. 4, n. 1, p. $5-45,1983$.

SILVA, Giliad. Teoria do dinheiro em Marx: precisões teóricas. In: CIPOLLA, Francisco; AQUINO, Dayani (org.). 150 anos d'O Capital: atualidade de Marx. Curitiba: CRV, 2017. p. $39-66$.

TRIGG, Andrew B. Marxian Reproduction Schema: Money and aggregate demand in a capitalist economy. Londres/Nova Iorque: Routledge, 2006.

TRIGG, Andrew B. Marxian Reproduction Schema. In: BRENNAN, David, at al (org.). Routledge Handbook of Marxian Economics. Londres/Nova Iorque: Routledge, 2017. p. $215-224$.

TRIGG, Andrew B.; HARTWING, Jochen. Marx's reproduction schemes and the Keynesian multiplier: a reply to Sardoni. Cambridge Journal of Economics, vol. 34, p. $161-173,2010$. 